\title{
Cuticular Hydrocarbons of Heterotermes tenuis (Isoptera: Rhinotermitidae): Analyses and Electrophysiological Studies
}

Luciane G. Batista-Pereira ${ }^{a}$, Márcio G. dos Santosa ${ }^{\mathrm{a}}$, Arlene G. Corrêa ${ }^{\mathrm{a},{ }^{*} \text {, }}$ João B. Fernandes ${ }^{\mathrm{a}}$, Alberto Arab ${ }^{\mathrm{b}}$, Ana Maria Costa-Leonardo ${ }^{\mathrm{b}}$, Célia R. R. C. Dietrich ${ }^{\mathrm{b}}$, Dilmar A. Pereira ${ }^{\mathrm{b}}$, and Odair C. Bueno ${ }^{\mathrm{b}}$

a Departamento de Química, Universidade Federal de São Carlos, 13565-905 - São Carlos SP, Brazil. E-mail: agcorrea@dq.ufscar.br

b Departamento de Biologia e Centro de Estudos de Insetos Sociais, Instituto de Biociências, UNESP, 13506-900 - Rio Claro - SP, Brazil

* Author for correspondence and reprints requests

Z. Naturforsch. 59c, 135-139 (2004); received April 11/June 10, 2003

Termites have become an important pest of Eucalyptus and Pinus reforestations, sugarcane and other cultures. An alternative for the control of this pest would be the use of attractive traps that take in account the social behavior of these insects. Diverse factors are important for the insects in the localization of the habitat and the choice of the food and specific odors can facilitate this. Studies referring to Heterotermes tenuis (Isoptera: Rhinotermitidae) are scarce. The objective of this work was to analyze the tergal cuticular extract of $H$. tenuis and determine the selectivity and sensitivity of its antennae to the components of this extract by electroantennography (EAG). The composition of the cuticular extract was determined by GC-MS analysis. The hydrocarbons found were restricted to linear alkanes, being most abundant $\mathrm{C}_{24}$ to $\mathrm{C}_{27}$ that comprises $c a .65 \%$ of the total. Olefins were not detected. EAG and behavioral test responses to the cuticular hydrocarbons were greater and significantly different from the control and the high selectivity of the antennae to the extract indicates its potential as chemical messenger. Cuticular hydrocarbons mixture is species-specific and can be used to identify a given taxon without the diagnostic castes, soldiers or imagoes. Difference in the composition appears to relate with the type of habitat of specie.

Key words: Heterotermes tenuis, Cuticular Hydrocarbons, Electroantennography

\section{Introduction}

Termites are abundant and diverse in most parts of South America, particularly in tropical lowland forests, savannas (Cerrado) and grasslands. Several native termite species have been reported as agricultural and forest pests. The main pest species belong to Rhinotermitidae (Heterotermes and Coptotermes) and Termitidae (Cornitermes, Procornitermes, Syntermes and Nasutitermes). The most affected crops by $H$. tenuis in South America are sugarcane, upland rice, maize, cotton, soybean, coffee, cassava, Eucalyptus and Pinus reforestations (Berti Filho, 1995).

The problems with termites attacking commercial forests as Eucalyptus and Pinus have increased in Brazil and H. tenuis is reported attacking trunks of adult trees (Berti Filho, 1995). In São Paulo State, in the sugarcane crops, H. tenuis constitutes one of the most frequent and distributed pests being able to cause damages up to $10 \mathrm{t} / \mathrm{ha} /$ year (Arrigoni et al., 1989).
Studies referring to $H$. tenuis are scarce; therefore its occurrence as pest in Brazil is relatively recent. Species of the Rhinotermitidae family live in diffuse (spread) nests in the soil. When active in foraging behavior, they make "shelter tubes" of soil material mixed with their saliva and fecal matter. They feed of the wood in decomposition and often attack vital parts of the plants like trunks and roots (Macedo, 1995).

Placing persistent insecticidal barriers in the soil around the roots has conventionally prevented damage to plants by subterranean termites. In the past, organochlorines (lindane, aldrin, dieldrin, chlordane and heptachlor) were applied almost exclusively as seed dressing or to the soil in planting holes or as furrows treatments. With the prohibition of these insecticides, alternatives for control of subterranean termites more ecologically acceptable that traditional chemical control measures become necessary. Researches with new chemicals of low environmental impact are being carried out, as well as alternative methods like biological con- 
trol with entomopathogenic fungi and physical barriers as plastic cylinders. Another alternative is the use of attractive bait for termites monitoring. It is generally performed by means of coil-corrugated cardboard, inside of a plastic bottle (Almeida and Alves, 1995; Wilcken and Raetano, 1995). Insects use several factors for localization of the habitat and choice of the food. In some cases, specific odors facilitate this localization and the identification of the alimentary source (Hubbell and Wiemer, 1983). For the best understanding of the interactions mediated by odors, i.e., semiochemical, it is necessary to study the aspects involved in the olfactory perception of these compounds through electroantennographic experiments (EAG). Some authors suggested that cuticular hydrocarbons might act as semiochemicals (Howard and Blomquist, 1982). At the present, the use of semiochemical as a possible attractant for $H$. tenuis is unknown.

The electroantennographic technique which measures electrical activities of the insect antennae in response to olfactory stimulus has been used for decades to evaluate the sensitivity of the chemical receptors to semiochemicals. To date, the use of this technique for $H$. tenuis antennae has not been published. Thus, the objective of this research work was to analyze the tergal cuticular extract of $H$. tenuis and determine the selectivity and sensitivity of its antennae to components of this extract by electroantennography (EAG).

\section{Materials and Methods}

\section{Collection of the insects}

$H$. tenuis workers were collected in the agricultural zone of Indiaporã, located in the northwest of São Paulo State, Brazil, from January to February 2000. The collection was carried out with cylindrical corrugated cardboard baits $(10 \mathrm{~cm}$ diameter, $15 \mathrm{~cm}$ height) buried under soil, $20 \mathrm{~cm}$ deep, next to poles infested with this termite species.

\section{Preparation of $H$. tenuis extracts for the chemical analysis}

The H. tenuis extract was prepared in the Laboratory of Termites, Biotério do Instituto de Biologia, Universidade Estadual Paulista, Rio Claro, SP. For the preparation of the extract for EAG bioassays and chemical analyses 250 workers of $H$. tenuis were used. The abdomens were sectioned, under a stereomicroscope and the guts removed, remaining only the tergites, which were extracted for $24 \mathrm{~h}$ in $3.0 \mathrm{ml}$ purified hexane. The extract was concentrated to about $500 \mu \mathrm{l}$ and stored at $-18^{\circ} \mathrm{C}$ for further analysis.

\section{Chemical analysis}

The extracts were analyzed by gas chromatography in a Shimadzu 17-A chromatograph equipped with DB-1 column $(30 \mathrm{~m} \times 0.25 \mathrm{~mm}$ i.d. $0.25 \mu \mathrm{m}$ film thickness; J \& W Scientific, Folsom, California) coupled to a Shimadzu QP 5000 mass spectrometer, using helium as carrier gas. Injections of $1 \mu \mathrm{l}$ of splitless tergal cuticular extracts were made at $250{ }^{\circ} \mathrm{C}$, using a temperature program of $60^{\circ} \mathrm{C} /$ $1 \mathrm{~min}, 2^{\circ} \mathrm{C} / \mathrm{min}$ to $240^{\circ} \mathrm{C}$, then $5^{\circ} \mathrm{C} / \mathrm{min}$ to $280^{\circ} \mathrm{C}$ held for $10 \mathrm{~min}$. Electron impact mass spectra $(70 \mathrm{eV})$ were obtained in the $\mathrm{m} / \mathrm{z}$ range of $33-250$.

\section{Electroantennographic (EAG) bioassays}

H. tenuis antenna was excised (pulled out of the head) by means of a forceps and a few segments were cut off at the base and the tip (Bjostad, 1998). The antenna was then fixed between two stainless steel electrodes by placing the base and tip into droplets of an electrically conductive gel (Spectra 360 ${ }^{\circledR}$ electrode gel; Parker, Orange, New Jersey) applied onto the metal electrodes. The specimen with the antennal preparation was placed in such a way that the humidified air directed the compounds eluted from the stimulus delivery over the antenna. The antennal responses were amplified and recorded with a data acquisition controller and software EAG (Syntech, Hilversum, The Netherlands).

The EAG experiments were performed in order to elucidate the selectivity of the antennal receptors of $H$. tenuis. To evaluate the EAG response the compounds were released from Pasteur pipettes containing a piece of filter paper (circa $0.8 \mathrm{~cm}^{2}$ ) impregnated with $5 \mu \mathrm{l}$ of the $H$. tenuis cuticular extract and passed over the antennae. One Pasteur pipette containing a filter paper impregnated with $5 \mu \mathrm{l}$ of the hexane solvent was used as control. The puff containing the tergal cuticular extract of $H$. tenuis was delivered into a continuously humidified and purified air stream of $1.2 \mathrm{l} /$ min, passing for $0.3 \mathrm{~s}$ through the impregnated filter paper in the pipettes. Control stimulation was made at the beginning and at the end of every series of EAG experiments. The H. tenuis cuticular 
extract was then applied at intervals of $90 \mathrm{~s}$ and tested using 10 antennae of $H$. tenuis workers.

\section{Behavioral bioassay}

The activity of tergal cuticular extracts in termites was performed by a Y-choice bioassay. $H$. tenuis workers of the last instar were immobilized under low temperature and by means of a forceps, under a stereomicroscope; all the tergites were removed without any remains of fat body tissue or digestive tract. The tergites were extracted for $24 \mathrm{~h}$ in $2.0 \mathrm{ml}$ purified hexane and stored at $-18^{\circ} \mathrm{C}$ until analysis. The extract was concentrated to about $10^{-2}$ worker equivalents $/ \mu \mathrm{l}(\mathrm{WE} / \mu \mathrm{l})$, which in preliminary bioassays showed high activity in termites. For the control purified hexane was used.

The extract of tergites was assayed using a Ychoice bioassay on filter paper discs $(15 \mathrm{~cm}$ in diameter). On the Y stem $(3 \mathrm{~cm})$ and on one of the $\mathrm{Y}$ branch $(7 \mathrm{~cm})$, the tergite extract was drawn with an adjustable micropipette (Boeco, Hamburg, Germany) containing $1 \mu \mathrm{l}$ of extract per $1 \mathrm{~cm}$ of trail. Another extract of pure solvent was placed on the other Y branch. One individual was gently deposited from a small perspex vial onto the $\mathrm{Y}$ base. The bioassay was repeated 30 times for both workers and soldiers. For an activity test, the distance covered by each individual was observed. The response was considered positive if the individual covered the $Y$ since its base up to tip of each branch. For each test a new individual and a new paper were used to avoid trail deposition.

\section{Statistics analysis}

The mean values of the electroantennographic (EAG) responses were calculated automatically by software EAG for Windows. The mean responses of the different compounds were submitted to ANOVA for statistical analysis and compared using the Tukey test $(\mathrm{P}<0.05)$. For the choice test, the number of termites that chose one trail was recorded and the data were compared by a Monte-Carlo test (Vaillant and Derridj, 1992), based upon chi-square at level of $\mathrm{P}<0.05$.

\section{Results and Discussion}

The hexane extract of tergal cuticles of $H$. tenuis workers was analyzed by GC-MS. Eleven components were identified as linear aliphatic hydrocarbons. They are the main constituents of the cuticular extract, and correspond to a homologous series initiating in eicosane, and finishing in triacontane. The corresponding percentage of each component in the extract (\%) is respectively: $0.8,2.2,2.5,3.1$, 3.1, 3.3, 3.5, 3.4, 2.5, 1.6 and 1.0.

The identification of these substances was made on the basis of the mass spectra analysis, as well as co-injection of the extract with standards, in this case that commercially available hydrocarbons [triacontane $\left(\mathrm{C}_{30} \mathrm{H}_{62}\right)$, pentacosane $\left(\mathrm{C}_{25} \mathrm{H}_{52}\right)$ and heneicosane $\left(\mathrm{C}_{21} \mathrm{H}_{44}\right)$ ], besides confirming its presence, had corroborated to an interpolation that confirmed the existence of other hydrocarbons that complete the homologous series. For this, the Kovats retention index was determined (Adams, 1995).

According to Woodrow et al. (2000) and Haverty et al. (2000), the cuticular hydrocarbons are divided in two different groups. The first group is comprised of normal alkanes, monomethylalkanes and olefins in the range of 23 to 27 carbons. The other group is comprised of higher molecular weight olefins or methyl branched compounds with carbon numbers in the range of 37 to 45 . The $n$-alkanes probably contribute to the largest degree of waterproofing of all cuticular hydrocarbons due to their closely-packed nature. Alkenes with low molecular weight probably are used to moderate lipid viscosity. Because insects cannot synthesize $n$-alkanes longer than 34 carbons (Haverty et al., 2000), long chain alkenes might exert a dual role of regulation viscosity and retaining water at higher temperatures, given the lack of superior, high-molecular-weight alkanes. Page et al. (2002) reported that Heterotermes sp. specimens produce a continuous 9,17-dimethylalkanes series from $\mathrm{C}_{27}$ to $\mathrm{C}_{30}$, and a 9,19-dimethylalkanes series from $\mathrm{C}_{28}$ to $\mathrm{C}_{30}$. They also produce 9,21-dime $\mathrm{C}_{29}$ and 9,21-dime $\mathrm{C}_{31}$. These dimethylalkanes characterized in Heterotermes sp. have not been identified in H. tenuis. This specie presents the profile of the first group of hydrocarbons, therefore the alkanes are linear and the carbon number varied from 20 to 30, and there are no olefins. The olefins are characteristic of the relative species to the families Kalotermitidade and Termopsidae, but other species of subterranean termites of the Rhinotermitidae often contain a significant fraction of olefins in the cuticular hydrocarbons mixture as Reticulitermes virginicus, $R$. flavipes and $R$. hageni (Jenkins et al., 2000). However, in Coptotermes vastator and $C$. formosanus species was not evidenced the presence of olefins (Haverty et al., 
Table I. Types and relative percentage (\%) of cuticular hydrocarbons of three species of Rhinotermitidae termites.

\begin{tabular}{|c|c|c|c|}
\hline \multirow[b]{2}{*}{ Hydrocarbons } & \multicolumn{3}{|c|}{ Species } \\
\hline & C. formosanus ${ }^{\mathrm{a}}$ & C. vastator ${ }^{\mathrm{a}}$ & H. tenuis ${ }^{\mathrm{b}}$ \\
\hline Olefins ${ }^{\mathrm{c}}$ & 0 & 0 & 0 \\
\hline$n$-Alkanes ${ }^{\mathrm{d}}$ & 2.5 & 15.5 & 95.0 \\
\hline Methyl-branched alkanes & 97.0 & 83.0 & 0 \\
\hline
\end{tabular}

a Coptotermes formosanus Shiraki and Coptotermes vastator Light, endemic and introduced species in Hawaii, respectively (Haverty et. al., 2000).

b Heterotermes tenuis endemic species from Brazil.

c Olefins: comprising monoenes, dienes and trienes.

d $n$-Alkanes: homologue series $\left(\mathrm{C}_{20}\right.$ to $\left.\mathrm{C}_{30}\right)$.

e Very diversified mixture of compounds with chain ranged from $\mathrm{C}_{25}$ to $\mathrm{C}_{39}$.

2000), corroborating with the results found for $H$. tenuis. C. formosanus and C. vastator present aliphatic hydrocarbons with different structures of $H$. tenuis, since the linear alkanes are minority while the most abundant are the branched ones (Table I).

The electroantennography (EAG) techniques have been extensively used for moths (Lepidoptera), mosquitoes (Diptera), aphids (Homoptera), beetles (Coleoptera) and other insect orders (Bjostad, 1998), however it is unknown for Isoptera mainly $H$. tenuis species. In this work, we have carried out electroantennographic experiments with $H$. tenuis antennae, and they were effective because the depolarization of the antenna for different stimulation and the response was selective. Then, it was demonstrated that the $H$. tenuis antennae possess chemoreceptors for the tergal cuticular extract (Fig. 1). The mean action potential recorded was $5099.2 \mathrm{mV}$ for tergal cuticular extract of workers and $2597.6 \mathrm{mV}$ and $2288.6 \mathrm{mV}$ for the hexane and air controls, respectively. The mean responses obtained for tergal cuticular extract of $H$. tenuis workers were significantly higher than mean response for controls (Fig. 2).

In the behavioral test of choice the total preference (Monte Carlo test, $\mathrm{p}<0.05$ ) for cuticular ex-
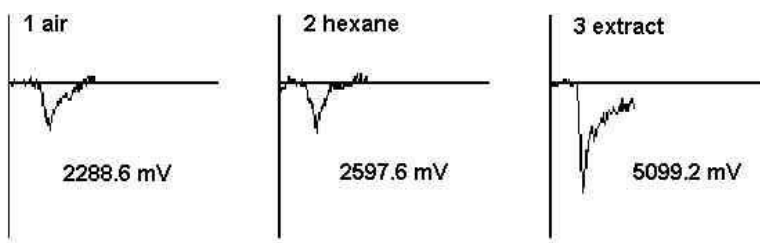

Fig. 1. Eletroantennograms $(\mathrm{mV})$ of H. tenuis workers as a response to tergal cuticular extract, hexane and air controls $(\mathrm{N}=10$ antennae $)$.

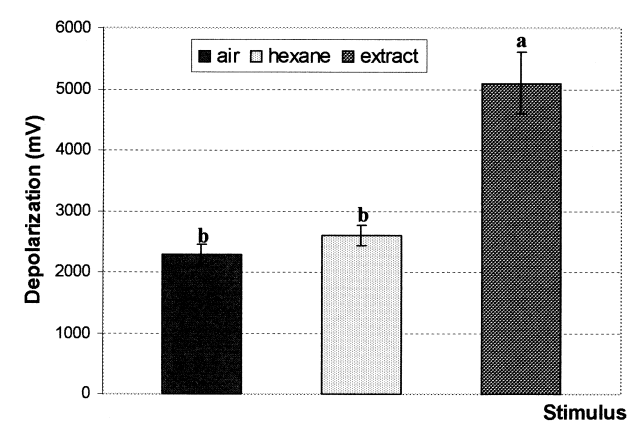

Fig. 2. Electroantennographic (EAG) response $(\mathrm{mV})$ of H. tenuis workers to different stimuli: air, hexane, and tergites extract ( $\mathrm{N}=10$ antennae). The stimulus was delivered from impregnated filter paper by using a continuously humidified and purified air stream of $1.2 \mathrm{l} / \mathrm{min}$. Means followed by the same letters are not different by Tukey test $(\mathrm{p} \leq 0.05)$.

tract in the concentration of bigger activity $\left(10^{-2}\right.$ tergites $/ \mu \mathrm{l})$ was verified for workers and soldiers (Table II), confirming the results obtained by the electroantennographic study. The high selectivity of the antennae of $H$. tenuis workers to the extract indicates its potential as a chemical messenger.

Table II: Choice bioassay for $H$. tenuis between extracts of tergites and control.

\begin{tabular}{ccc}
\hline \multirow{2}{*}{ Caste } & \multicolumn{2}{c}{ Extract } \\
\cline { 2 - 3 } & Tergites & Control \\
\hline Workers $^{\mathrm{a}}$ & $30^{*}$ & 0 \\
Soldiers & $30^{*}$ & 0 \\
\hline
\end{tabular}

a Last instar worker.

* Significant difference (Monte Carlo test, $\mathrm{p}<0.05$ ). $\mathrm{N}=30$ repetitions for each caste. 
The composition of the hydrocarbons mixture is genetically controlled (Coyne et al. 1994). Cuticular hydrocarbons mixture is species-specific and can provide an alternative method to identify a given taxon without the diagnostic castes, soldiers or imagoes (Haverty et al., 1991). Hydrocarbons might also serve as an important semiochemical cues for caste and species recognition (Howard and Blomquist, 1982). Thus, the results obtained by the electroantennographic analysis indicate that $H$. tenuis workers recognize the cuticular hydrocarbons of its proper species, or even of the proper colony. In accordance with Haverty et al.

Adams R. P. (1995), Identification of Essential Oil Components by Gas Chromatography Mass Spectroscopy. Allures Publishing, New York, p. 469.

Almeida J. E. M. and Alves S. B. (1995), Seleção de armadilhas para captura de Heterotermes tenuis (Hagen). An. Soc. Entomol. Brasil 24, 619-624.

Arrigoni E. B., Almeida L. C., Kasten Jr. P., and Precetti A. A. C. M. (1989), Distribuição de espécies de cupins, em cana-de-açúcar, em unidades cooperadas das regiões de Jaú e Sertãozinho. Bol. Tec. Copersucar 48, $38-47$.

Berti Filho E. (1995), Cupins e florestas. In: Alguns Aspectos Atuais da Biologia e Controle de Cupins (Berti Filho E. and Fontes L. R., eds.). Fundação de Estudos Agrários Luiz de Queiroz, Piracicaba, pp. 127-140.

Bjostad L. B. (1998), Electrophysiological methods. In: Methods in Chemical Ecology: Chemical Methods, Vol. 1 (Haynes K. F. and Millar J. G., eds.). Chapman and Hall, London, pp. 339-369.

Coyne J. A., Crittenden A. P., and Mah K. (1994), Genetics of a pheromonal difference contributing to reproductive isolation in Drosophila. Science 265, $1461-1464$.

Haverty M. I., Page M., Thorne B. L., and Escoubas P. (1991), Cuticular hydrocarbons: species and population-level discrimination in termites. USDA Forest Service Gen. Tech. Report PSW 128, 15-23.

Haverty M. I., Woodrow R. J., Nelson L. J., and Grace J. K. (2000), Cuticular hydrocarbons of termites of the Hawaiian Islands. J. Chem. Ecol. 26, 1167-1192.

Howard R. W. and Blomquist G. J. (1982), Chemical ecology and biochemistry of insect hydrocarbons. Annu. Rev. Entomol. 27, 140-172.
(2000), the difference in composition of cuticular hydrocarbons mixture is also related to the type of habitat of each species. The chemical analysis of the extract demonstrated a profile of termite cuticular hydrocarbons similar to termites that inhabit subterranean and humid places, which is the same for $H$. tenuis.

\section{Acknowledgements}

The authors thank Elektro Eletricidades e Serviços S. A., CNPq, FAPESP (Brazil), and IFS (Sweden) for financial support.

Hubbell S. P. and Wiemer D. F. (1983), Host plant selection by an Attini ant. In: Social Insects in the Tropics, Vol. 2 (Jaisson P., ed.). University of Paris Press, pp. 233-254.

Jenkins T. M., Harvety M. I., Basten C. J., Nelson L. J., Page M., and Forschler B. T. (2000), Correlation of mitochondrial haplotypes with cuticular hydrocarbon phenotypes of sympatric Reticulitermes species from the Southeastern United States. J. Chem. Ecol. 26, $1525-1542$.

Macedo N. (1995), Atualização no controle de cupins subterrâneos em cana-de-açúcar. In: Alguns aspectos atuais da biologia e controle de cupins (Berti Filho E. and Fontes L. R., eds.). Fundação de Estudos Agrários Luiz de Queiroz, Piracicaba, pp. 121-126.

Page M., Nelson L. J., Forschler B. T., and Haverty M. I. (2002), Cuticular hydrocarbons suggest three lineages in Reticulitermes (Isoptera: Rhinotermitidae) from North America. Comp. Biochem. Phys. B 131, 305324.

Vaillant J. and Derridj S. (1992), Statistical analysis of insect preference in two-choice experiments. J. Insect Behav. 5, 773-781.

Wilcken C. F. and Raetano C. G. (1995), Controle de cupins em florestas. In: Alguns Aspectos Atuais da Biologia e Controle de Cupins (Berti Filho E. and Fontes L. R., eds.), FEALQ, Piracicaba, pp. 141154

Woodrow R. J., Grace J. K., Nelson L. J., and Haverty M. I. (2000), Modification of cuticular hydrocarbons of Cryptotermes brevis (Isoptera: Kalotermitidae) in response to temperature and relative humidity. Environ. Entomol. 29, 1100-1107. 